Article

\title{
The UK Scholarly Communication Licence: Attempting to Cut through the Gordian Knot of the Complexities of Funder Mandates, Publisher Embargoes and Researcher Caution in Achieving Open Access
}

\author{
Julie Baldwin ${ }^{1}$ (D) and Stephen Pinfield ${ }^{2, *(1)}$ \\ 1 UoN Libraries, University of Nottingham, Nottingham NG7 2RD, UK; Julie.Baldwin@nottingham.ac.uk \\ 2 Information School, University of Sheffield, Regent Court, 211 Portobello, Sheffield S1 4DP, UK \\ * Correspondence: s.pinfield@sheffield.ac.uk; Tel.: +44-0114-222-2649
}

Received: 8 June 2018; Accepted: 4 July 2018; Published: 13 July 2018

check for updates

\begin{abstract}
Whilst take-up of open access (OA) in the UK is growing rapidly due partly to a number of funder mandates, managing the complexities of balancing compliance with these mandates against restrictive publisher policies and ingrained academic priorities, has resulted in UK higher education institutions (HEIs) often struggling with confused researchers, complex workflows, and rising costs. In order to try to address this situation, the UK Scholarly Communication Licence (UK-SCL) was formulated to bypass the root causes of many of these challenges by implementing a licensing mechanism for multiple-mandate compliance in one single policy. This is the first empirical study to focus on the genesis of the UK-SCL and how its implementation has been conceived thus far. A qualitative research method was used, taking the form of 14 semi-structured interviews with key stakeholders from the initiative across the UK. The results indicate that those working within UK HEIs are concerned with the complexity of the current OA policy landscape and are frustrated with the inertia within the current system, which has resulted in higher costs, further publisher restrictions, and has not addressed the underlying tensions in academic culture. The UK-SCL is seen by its initiators as a way to achieve further transition towards OA and take back some element of control of the content produced at their institutions. The study concludes by modelling the ways in which the UK-SCL is intended to impact relationships between key stakeholders, and discussing possible implementation futures.
\end{abstract}

Keywords: copyright; UK-SCL; Scholarly Communication Licence; Scholarly Communications; higher education institutions; open access; licensing

\section{Introduction}

The open access (OA) environment is a complex and rapidly changing one, which Banks describes as somewhere between "wildly exciting" and "terrifying" [1] (p. 37). Higher Education Institutions (HEIs) are now often engaged in promoting OA but in doing so frequently face the challenging task of trying to comply concurrently with a number of funder and government OA mandates, whilst at the same time taking account of increasingly complex publisher policies [2]. Policy compliance is often coordinated by university libraries [3], who find themselves in the difficult position of trying to balance the need to comply with mandates with the desire to deliver attractive services to researchers encourage the adoption of OA practices [4]. This is made particularly challenging in a landscape that may be highly volatile-one where there may be widespread agreement with the principle of OA, but 
where there is no consensus on how it can be best achieved. Whilst a whole range of different policies aimed at encouraging greater $\mathrm{OA}$ are being introduced by different agencies, they are often lacking in consistency in terms of specific actions recommended.

In the UK, the policy landscape is currently particularly complex, with some funders focusing on promoting 'gold' OA (OA publication in journals) and others 'green' OA (deposit of copies of outputs in OA repositories). The former position was taken up by the publicly-funded Research Councils (formerly known as RCUK) following the recommendations of the Finch Report in 2012, which concluded that an APC-funded gold OA system was most likely to enable a sustainable OA environment [5]. The UK Research Councils and other medical research charities (the latter coordinating their approach in the Charities Open Access Fund, or COAF) introduced policies which explicitly favoured gold OA and made funds available in the form of block grants to institutions for payment article-processing charges (APCs). Controversially, the Research Councils and COAF permitted payment of APCs for articles in hybrid journals (subscription journals allowing payment of APCs to make particular articles OA), an approach designed as a transition mechanism. However, as these gold-centric policies were becoming more embedded in UK HEIs, the government funding body formerly known as the Higher Education Funding Council for England (HEFCE), and partner organisations in other constituent countries of the UK, launched a green-centric policy. This stated that works to be submitted for the national research quality assessment process, the Research Excellence Framework (REF), would only be eligible for consideration if made available from an OA repository, with an emphasis on institutional repositories [6].

In the period following the introduction of these policies, their consequences have become increasingly clear. The UK has accelerated in its adoption of OA beyond global averages, and this has included greater uptake of both the gold and green routes, particularly gold $[7,8]$. UK uptake of gold OA has, however, been dominated by hybrids, and the payment of APCs involved has led to an increase in overall costs for UK HEIs. Although some offsetting arrangements (adjusting subscription and APC prices in relation to each other) have been put in place by some publishers, both APC costs and subscription costs have continued to rise in parallel, in addition to new administrative costs experienced by institutions $[9,10]$. At the same time, deposits in repositories have also risen, but a large number of these are not made available in an OA form immediately since they are subject to embargoes. The REF policy states that items should be deposited in repositories "upon acceptance" by a journal (although this has up until now been implemented in a more relaxed form of "upon publication") [6], but it has become increasingly apparent that embargo policies written into publisher contracts with authors mean that many deposited items cannot then be made available without considerable delay [11].

Since 2012, a large number of publishers have introduced or strengthened embargoes. Embargoes constrain how outputs may be made available in a green OA form, often involving variable arrangements relating to 'where', 'when', 'why' deposited outputs can be made OA, and 'what' can be deposited [8,12]. With regard to 'where', publisher regulations may differ between deposits in institutional repositories or personal webpages, for example. With regard to 'when', deposits may often be embargoed for between 6 and 24 months following publication. With regard to 'why', a number of publishers have introduced policies which allow 'voluntary' deposits to be made available immediately upon publication, but deposits made in compliance with mandates to be subject to time embargoes. With regard to 'what', very few publishers allow the published version of record (VoR) to be made available, only permitting deposit accepted author manuscripts (AAMs).

The administration of green OA therefore, like the environment as a whole, has become increasingly complex and institutions are having to work hard to navigate the complexities of managing technologies and workflows which support both green and gold OA. Alongside this, the traditional publishing system has remained remarkably resilient [13]. Embargoes are designed to ensure the ongoing viability of the subscription model, and hybrid journals have also enabled the continuation of journals based fundamentally on a subscription business model, whilst also opening up a new 
income stream for publishers in the form of APCs. Service providers in HEIs are, therefore, working in a multi-policy environment trying to scale-up their services to meet growing demand whilst also dealing with an increasingly complex publishing landscape which now includes the challenge of the rising costs of open access alongside those of rising subscription costs.

It is in this context that a growing number of UK HEIs have set in motion development of the UK Scholarly Communications Licence (UK-SCL). Starting in 2015, led by Imperial College London, the UK-SCL initiative has consisted of the development of an open access licence and model policy, based on an approach originally developed at Harvard University in the USA [14,15]. The Harvard model was launched in 2008 and has now been implemented in more than 70 institutions worldwide, and is reported to have met with a good level of acceptance and success [14]. The licence is designed to allow authors and institutions more control over the research publications which they produce. The UK-SCL is an iteration of the Harvard licence adapted for UK law [16] which allows authors to grant the university a non-exclusive licence to make their AAM available without delay through the university's open access repository under the terms of a Creative Commons licence (CC BY-NC) (see draft model policy in Appendix B). Thus, it aims to support the institutional transition to OA by streamlining copyright processes [1]. The initiative is a bold approach designed to allow for a one-step process for OA mandate compliance, through the creation of a non-exclusive licence held by the university and which is binding on publishers [14]. It focuses on re-use rights retention, to allow items to be made available in repositories without delay, as a way of accelerating communication of research results and ensuring compliance with funder requirements [17].

The UK-SCL implementation is being driven by a group of institutions working in concert to formally adopt the licence together [18]. While the option for authors to retain copyright is not a new concept in itself [19-21], this consortial approach aiming to provide blanket coverage for all participating institutions' academics and their outputs is an innovative and ambitious one [1]. In many respects, it seems to represent an attempt to cut through the 'Gordian knot' of challenges associated with the current complex scholarly communication environment by providing a single solution. Whilst often initiated by university libraries, the approach has gained formal support in some institutions, as well as the endorsement of a number of sector-wide bodies [17]. Now more than two years into the planning process, the UK-SCL has sparked lively debate within publishing and academic circles [22]. It remains untested in UK law, and some of the debate has focused on the legal aspects of the initiative; it does however, also raise a whole range of other controversial arguments around issues such as research management, institutional policies and academic cultures. It is, therefore, timely to provide an evidence-based overview of the proposed policy and its development to date, with the hope of informing future practice in this area. This study is the first in the literature to provide an empirical investigation of the UK-SCL.

This study draws on data collected from detailed interviews of 14 key stakeholders connected with the UK-SCL initiative, most of whom were directly involved in inputting into its design and implementation, conducted at a time of relative maturity in the planning process. Interviews focused on perceptions of the UK-SCL's potential benefits and challenges, key findings arising from which are reported here. The study, firstly explores the drivers which led to its development, including the perceived systemic problems of the UK scholarly communication environment it is designed to help to address. It then highlights what are expected to be the benefits and challenges of implementing the licence. It goes on to discuss major issues arising from plans to implement the licence in institutions. Following presentation of the findings from interviews, a number of comments are made evaluating the key features of the UK-SCL, including presentation of a model which maps out the issues and relationships involved in the initiative. To conclude, issues associated with the UK-SCL's likely future is then discussed. 


\section{Literature Review}

\subsection{Rise of Open Access and Mandates}

Discussions of open access in the literature have shifted in recent years from focusing on the principles of OA to practical issues associated with its widespread implementation [23-25]. OA implementation, however, is complex - whilst the idea of OA is relatively simple, embedding it in practice involves addressing a complex set of challenges [21,26]. Increasingly noted in the literature is the rise of OA mandates, their positive impact in driving change but also the challenges they create. Ayris et al. argue that mandates are particularly challenging as they make the landscape increasingly complex and highlight the conflicting interests of the various stakeholders involved [27]. There have also been widespread calls for greater coordination across OA policies $[2,28,29]$. No more so than in the UK, where the complex set of mandates from the former RCUK [30] and HEFCE [6] (now both under the auspices of newly-formed government agency, UK Research and Innovation, UKRI), plus many medical research charities and other agencies such as the European Union, have created significant set of challenges for OA implementation [1,26].

Whilst mandates are complex, many argue they make an important contribution to OA uptake $[9,31,32]$. Jubb et al., have recently produced a report highlighting the rapid rise of green and gold OA uptake in the UK-rises which can be reasonably attributed, at least in part, to strong OA policy mandates [8]. However, others argue that these mandates alone cannot transform the scholarly publishing environment [33,34], emphasising that major barriers remain in author behaviours and academic cultures.

\subsection{Copyright and Culture}

One of the key challenges in this area is reconciling the copyright implications of funder open access mandates with the conventional publishing system and authors' understandings of their own intellectual property. With the advent of the Web and the rise of OA, copyright of scholarly publications has become an area of dispute, given the myriad new opportunities to share and distribute content [13]. In the early 2000s, librarians and OA advocates commonly argued for change through encouraging author copyright-retention $[19,20,35]$. However, as the OA agenda developed, there was a shift to a focus on marketing to researchers, implementing new workflows, and getting services up and running in practice, and this seems to have meant that copyright issues per se received less interest, at least in the literature. However, the rise of OA and OA mandates has pushed copyright once more to the foreground, highlighting issues of licensing agreements, academics' understandings of copyright, and institutional policies on intellectual property $[2,21,26,36]$. In particular, the relationship between authors and their institutions in the area of copyright has become an area of focus. In 2000, Weedon carried out a comprehensive study of UK HEI Intellectual Property (IP) policies, showing $69 \%$ had some general claim to the IP of its scholars [37]; however, this is significantly before widespread OA practices were adopted. More recently, Gadd [36] has reported another investigation similar to [37] Weedon's, showing that now $86 \%$ of HEIs have made a general claim to own IP, possibly highlighting the greater prominence given to this issue by institutions and moves towards policies framed around treating copyright as "shared" between the author and institution.

Despite such moves, custom and practice in HEIs has normally been that institutions waive any right to be involved management of copyright, allowing authors themselves to dispose of copyright as they think appropriate. Traditionally, authors have been required to transfer exclusive rights to publishers at the point of acceptance of their work for publication, and many have argued that this has inhibited OA development $[1,38,39]$. Ober, in 2006 questioned handing all rights over to publishers, arguing that this contributed to their increasing profits [20], and Suber warned of a permissions crisis, where the publishers' business models depend on maintaining access barriers acquired through owning the copyright [21]. Nevertheless, the scholarly reward system continues to mean that academics trade their copyright to publish in their preferred journals, which has thus 
far been seen as more advantageous to them compared with any benefits they could gain from retaining their copyright $[26,32,40]$. It has been shown that many academics believe that publishing in traditional journals is most likely to contribute to promotions and pay rises, rather than making their work available in an OA form [41-43].

The behavioural incentives for researchers are crucial, and the dominance of the journal impact factor (JIF) is a common focus in this area of the literature. In particular, the circularity of a system based on the valuing of impact factors-where high impact factor journals, attract more submissions from authors conscious of the career value of publishing in such venues, which in turn increases the JIF-is often bemoaned $[24,44,45]$. One of the consequences of this system is that publishers of high-JIF journals find it easy to demand transfer of exclusive rights from authors, and so it is therefore argued, stifle innovative approaches to scholarly communication. Casadevall and Fang argue that this "Impact Factor Mania" [46] (p. 1), creates behavioural incentives in which publishing in high impact factor journals may result in individual benefits for authors, but causes them to act in ways that do not benefit the community as a whole. Negative consequences of this are to limit and delay the dissemination of research, confining it to subscribers only and preventing timely deposit in a repository. Fyfe et al. have recently tracked the development of notions of academic 'esteem' throughout the Twentieth Century and argue that the embeddedness of this phenomenon means that any new scholarly publishing model for OA needs to address it [39]. Rowley et al. concur and add that as academics are primary contributors to all scholarly publishing in the form of researchers, authors, editors and reviewers, it is vital to engage them in co-creating any new publishing model and the value-system around it [40].

This situation is compounded by the fact that many academic authors have only a hazy understanding of the complex copyright landscape that OA has highlighted [21]. This has led to a wide range of inconsistent behaviours. For example, many cite copyright confusion as an issue contributing to difficulties in populating IRs-authors worry that depositing their work in IRs may be in breach of copyright $[4,47,48]$. However, paradoxically, Jamali highlights the same issue of low copyright literacy but actually uses it to partly explain authors' willingness to risk copyright infringement by contributing to the scholarly social network, ResearchGate [49]. The study shows that over half of a sample of 392 articles on ResearchGate were not compliant with their publisher's policy, mostly through uploading the publishers' PDF, implying a lack of understanding of (or lack of respect for) publisher copyright policies. Such behaviour has been explained by distinguishing between "copyright culture" ("the range of copyright legislation, licenses, policies and practices that impact on scholarly activity") on the one hand and on the other, "scholarly culture" (which prioritises dissemination of works as long as moral rights of the author are respected) [50]. The lack of commonality between the cultures can lead to a kind of "cognitive dissonance" on the part of authors who will happily post illegal copies of papers on ResearchGate having already voluntarily assigned rights to a publisher.

\subsection{The Role of Libraries}

The increase in funder mandates and complexities associated with managing issues such as copyright, have necessitated an increased institutional focus on supporting researchers in dealing with these challenges, and this responsibility has often fallen to or been claimed by university libraries [51-54]. Keller claims this expansion of the library's role comes from the desire to best support its users' changing needs [55], similarly evidenced in Cox's 2017 study where he attributes new research support activity to accommodating researchers' growing expectations [56]. Much of this literature highlights new services libraries have begun providing in order to meet this researcher need, including institutional repositories (IRs), bibliometrics, OA support, data and journal hosting, and Research Data Management (RDM) [55,57,58]. Others further highlight the breadth of librarians' expertise, enabling them to advise on areas such as rights management, publishing, and discoverability [53]. A number of commentators have seen developments like this as evidence of the library assuming a clearer partnering role with researchers around managing the research lifecycle [56,59-62]. 
However, the nature of the scholarly rewards system, when combined with OA mandates, can cause significant challenges for librarians in supporting OA practices $[9,21,63,64]$. In the gold OA market, Pinfield argues that a main concern for librarians in this transitional period is the lack of market transparency publishers allow, making it difficult to evaluate the economics of OA [25]. It has been argued that, due to the oligopolistic position of large publishers [65], the market has "evolved into one in which the publisher tries to price its subscriptions according to each client's ability and willingness to pay, not according to average marginal cost for the publisher" [13] (p. 104). Lawson et al. further agree that the "black-box" finances in academic publishing are inhibiting evidence-based policy making, as it is impossible to understand the financial implications for new innovations [66] (p. 25). It has also been shown the Article Processing Charge (APC) market is included in this, with many highlighting the disparity between APC price levels, and in particular the trend of higher costs of hybrid than pure-gold journals [8,67]. Another economic factor which has been mentioned frequently is 'double-dipping' - paying twice for journal content through subscriptions and APCs $[13,68]$ - a particular concern in the UK because of funders' willingness to pay APCs for hybrid journals [10].

Others have also pointed to publisher practices for negatively impacting uptake of green OA, particularly through embargoes [11,24], arguing that with regard to IRs, publisher policies specifically "seek to blunt their impact" [11] (p. 468). These policies have become more restrictive over time [11,25,48], with Gadd and Troll Covey (2016) showing that the volume of time-embargoes, for example, has increased by $1000 \%$ since the inception of the SHERPA/RoMEO service, 12 years ago [12].

\subsection{Possible Solutions-Policy and Practice}

Much of the discussion around OA implementation has highlighted challenges, rather than suggested solutions. However, since the inception of OA, there has always been a perceived need to address the copyright implications of the transition towards greater OA, particularly through author rights-retention. An early advocate, Willinsky, argued for the need to abandon the traditional rights-transfer model and create a culture of copyright retention [19]. A study by Hoon and van der Graff examined new models for managing rights in an OA environment, such as author addendums, and found the majority of academics they surveyed preferred a rights-retention system [35].

There have since been numerous attempts to encourage rights-retention in practice. Most of these have been pitched at the level of the individual author, relying on authors to negotiate copyright retention with their publisher. This solution has, to date, looked unrealistic-both Bastos et al. and Suber agree that it is hard for individual authors to try to retain rights not normally allowed in the publisher's licence- "when authors stand alone, they have very little bargaining power against publishers" [21] (p. 128) and [69]. Other services have been set up to aid greater transparency. Prominent amongst these is SHERPA/RoMEO and its related suite of services [70], which provide information on copyright information and publisher and funder policies. Whilst such services have arguably been vital for academics and OA administrators in achieving greater adoption of OA, they do not tackle the underlying issues of copyright ownership and management. Such issues still need addressing and this can best happen, it has been argued, at an institutional level, rather than expecting individual authors to do it themselves [21,71]. An institutional contribution now seems to be essential, as it seems, so far, lone authors have had little success in challenging the traditional system or indeed little incentive to do so.

An institution-level approach of this type was pioneered by Harvard University in 2008 [17]. Commenting that unified action within an institution was best to encourage higher uptake of OA, Suber highlights how a number of other US institutions have subsequently adopted the Harvard approach [21]. Two studies which focus on this approach include Frankel and Nestor's study of the Harvard model, which examines the legalities and practicalities of implementing such a model elsewhere [72], although this is heavily based on the US legal system. The other is a study examining 
the prevalence of the model or similar types of licence addendums, which found that there are some policies using these, but that they are by no means common [73].

The author-retention copyright approach has now, however, been used as the basis of the UK-SCL, with Banks describing the rationale for it in 2016 [1]. Banks argues for a "frictionless service" [1] (p. 37), which she believes this new type of licence will enable. The UK-SCL initiative has since launched a website (UK-SCL.ac.uk) where it explains the details of the policy, highlighting the aims of the initiative are in keeping with funder aims, and defining its purpose to be "keeping ownership of academic research within the academic community_for visibility, impact, access and re-use" [17]. The provision in the UK-SCL that allows institutions to make AAMs available immediately in an OA repository under a Creative Commons licence crucially facilitates compliance with UK funder policy mandates [14]. It is emphasised that this policy is very much a transitional vehicle in the move towards openness and therefore allows temporary publisher waivers. These waivers, essentially offering embargoes of 6 months for STEM (Science, Technology, Engineering and Mathematics) subjects and 12 for AHSS (Arts, Humanities and Social Sciences) subjects, have been designed to ease the policy's implementation and have been described on the UK-SCL website as going "above REF OA minimum eligibility", reducing the minimum embargo periods for the REF policy of 12 months for Panels A and B (for STEM subjects), and 24 months for Panels C and D (for AHSS subjects) [17].

The initiative has, however, proved controversial. On the positive side, Gadd has described UK-SCL as an encouraging initiative which will be a useful starting point for discussions over ownership [36]. Fyfe et al. also recommend such an approach to HEI leaders, arguing that this model for copyright retention is an "appropriate rebalancing" [39] (p. 19) of rights, giving academics more responsibility over their own publishing decisions. However, some academics and publishers have been highly critical of UK-SCL. Arguments have been made that the new licence will inhibit scholarly publishing and reduce academic freedom for authors to publish in top journals [22,74,75]. In some cases this has included direct communications by publishers to try and influence their researcher community [76]. Much of the public discussions between the varied opinions has been tense and played out in blog comment sections and highlights the potential difficulties the two opposing sides will have in coming to a resolution, if at all.

The UK-SCL initiative is now at a mature stage in the planning cycle, although the final stages of implementation are still to be confirmed, following several delays [17]. It is widely acknowledged that putting policy such as this into practice will not be a simple process [63,77-79]. Policy of this sort is being made in a shifting and unpredictable landscape, meaning the timeline for implementation UK-SCL is constantly moving and needs continual re-evaluation. Implementing approaches such as the UK-SCL are also now being seen as part of introducing sustainable policies in wider areas of open research, and so are seen to be only one part of a larger push towards changing behaviours.

\section{Method}

This research aimed to build up a rich picture of the motivations of key stakeholders involved in planning or supporting the UK-SCL, and of their perceptions of challenges and expected benefits of this new policy. The research approach taken was, therefore, inductive, qualitative and exploratory. This allowed the issues around the licence to be explored in depth, giving weight to context [80]. To collect the data, semi-structured interviews were conducted in person. A purposive sample of 14 participants from across the UK was identified, all broadly from the library and information sector, mostly from HEIs at varying stages of planning UK-SCL implementation. Participants included library directors (three), members of the library senior management team with strategic responsibility for scholarly communication issues (six), and middle managers with direct responsibility for planning local implementation of the UK-SCL (three). In addition, two participants were from national agencies, rather than HEIs. This approach to sampling allowed a multi-faceted picture to emerge of the UK-SCL implementation from early to later stages, and also allowed both operational to strategic perspectives 
to be covered. The sample included members of the national UK-SCL implementers' group as well people managing implementation of the licence in particular local contexts.

These stakeholders were invited by email to participate in the study. A potential challenge for this project was that given the new and potentially sensitive nature of the research, participants may have been reluctant to take part. However, in the event, all those invited agreed to contribute. Table 1 shows more details of those who took part, including the contextual codes used in the reporting of the results below. Participant roles and titles have been excluded to ensure anonymity.

Table 1. Participants.

\begin{tabular}{cccc}
\hline Institution Type & $\begin{array}{c}\text { Implementation } \\
\text { Stage }\end{array}$ & $\begin{array}{c}\text { Contextual Code for } \\
\text { Quotations }\end{array}$ & $\begin{array}{c}\text { Number of Participating } \\
\text { Institutions }\end{array}$ \\
\hline Russell Group & Early adopter & RG-EA & 5 \\
Russell Group & Later adopter & RG-LA & 2 \\
Pre-1992 & Early adopter & Pre-92-EA & 2 \\
Pre-1992 & Later adopter & Pre-92-LA & 3 \\
HEI unaffiliated & N/A & H-U & 2 \\
\hline
\end{tabular}

An interview schedule was devised using the literature to inform its development (Appendix A), and a pilot study was undertaken. The interviews took place between 25 May and 21 June 2017 and varied in length between 30-75 min-with a semi-structured questioning approach, participants were given considerable latitude to discuss what they regarded as important. The research was given approval under the University of Sheffield Information School ethics approval process by the University of Sheffield Research Ethics Committee. The approach taken was based on the principles of voluntary participation, informed consent and anonymisation. At the beginning of the interviews, participants were provided with an information sheet and consent form to sign, and were given the opportunity to ask any questions. Furthermore, due to the slightly sensitive nature of the topic, full details of which had yet to enter the public domain, the interview schedule was emailed ahead of the interview to provide participants with a clearer idea of the scope of the project, and give them time to assess how best to participate in the interview. The interviews began with a situating question to discover the HEI's position in the implementation process, allowing for greater context for the remainder of the interview. To adapt to the differing positions of participants in the implementation process, as well as those who were HEI unaffiliated, the approach was then adapted and included additional questions as necessary to best fit the participant's context [81].

The data collected from the interviews was recorded and fully transcribed, and then thematic analysis was undertaken in an inductive style. The structured analysis method as laid out by Braun and Clarke was utilised, allowing for continued iteration, narrowing down and organising large quantities of data into broad concepts [82]. After becoming familiar with the data through re-reading transcripts, codes were identified from recurring features in the data, allowing for data to be logically segmented into more manageable categories. Codes were then grouped with other related codes. These were refined into wider themes and sub-themes, and checked across the whole of the dataset to confirm internal and external validity. Interview transcripts were analysed using the NVivo software. During the process all codes assigned in NVivo were 'data-driven' (that is derived from concepts and terminology adopted by participants themselves) and analysed for 'latent' topics (those implicit in the data) in addition to 'descriptive' (explicit) codes [82]. Quotations were then chosen to highlight specific themes and common issues arising from the research. Particular attention has been given to ensure that all these quotations indicate the full coverage of viewpoints by including multiple quotations from each participant. 


\section{Results}

\subsection{Why Is the Licence Needed?}

The data portrays a picture of a complex and rapidly-shifting environment. All of the participants described the rationale for introducing the UK-SCL as a response to the particular pressures created by current features of the scholarly communication landscape. There was a strong sense amongst the participants that whilst there had been positive moves in the direction of greater openness, the OA policy environment as currently formulated in the UK was becoming difficult to manage and sustain, with a multiple competing pressures which were increasingly hard to balance. It was felt that the combination of the inertia in the traditional publishing system, perverse academic behavioural incentives, sensitivities around copyright issues, combined with disharmonious OA policy mandates, all contributed to difficulties in managing OA in HEIs.

Underlying many of the comments made by participants was the view that there were fundamental systemic problems with the way scholarly communication is currently constituted:

"UK tax money funds research which then is created in the institution, is written up by academics within the institution, is refereed by academics in the universities, is then given away for free to a commercial third party with shareholders, who then charges us to buy it back. I mean who in their right mind would invent that as a model of disseminating research?" RG-EA.

The desire to work towards a different kind of system, particularly involving greater openness, was seen as important by all the participants. Many participants listed the UK-SCL as one of a number of OA-related initiatives in which they were involved, which included activities varying from setting up OA university presses to participation in wider initiatives such as Knowledge Unlatched. These initiatives were in general, like the UK-SCL in particular, seen as being aimed at producing a more sustainable OA environment. In this context, national initiatives, such as policy mandates were viewed as positive drivers, but there was still recognised to be considerable inertia in the system.

The scholarly reward system was highlighted as a root cause of many of the problems currently encountered, particularly with academics and institutions linking publication venue or publisher brand, rather than the extent of dissemination, with prestige. The perceived need to publish in particular journals often meant doing whatever it takes to get published, including authors signing over exclusive rights to publishers:

"... their priority is to get published, especially with certain publishers, and then therefore they will tend to do what is necessary in order for that to happen, without necessarily scrutinising the copyright statement". Pre-92-EA.

Participants felt that these practices were embedded within the scholarly culture, and to move forward in transitioning to and promoting openness, they would need to be addressed:

"There's hundreds of years' worth of precedence with this. So we want to move to a world where openness is rewarded and we move away from, sort of perceived journal prestige all the time and impact factors." RG-EA.

Bound up with scholarly notions of esteem was intellectual property and copyright. One interesting finding was the acknowledgement of the differences between codified copyright policy and informal copyright custom and practice. UK copyright law states that employers are usually the holders of copyright following the creation of a work by employees, and many HEI Intellectual Property Rights (IPR) policies reflect this. However, with the desire to protect academic freedom, part of which is often seen to involve freedom for authors to choose publishing venue in an unconstrained way, most institutions were reported to have traditionally waived any involvement in managing copyright for publications-a situation that would be difficult to disturb: 
"We've had the current [policy] in place for a number of years ... but we do not enforce the terms and conditions at all and that could be a problem, because we've acquiesced. We've allowed this situation through custom and practice to develop over a course of years." RG-LA.

This gap between policy and practice was seen as being reinforced by the complex and emotive nature of copyright and IPR, making it hard to advocate alternative approaches:

"... when you start talking about these issues, the complexity of it overlaid with the fact that people have that investment in it and feel like they don't want to lose out." Pre-92-LA.

Therefore, a lack of clarity, coupled with the complexity and academics' sense of personal ownership in the work they have produced, all contribute to difficulties balancing the different needs of the different actors (researchers, their institutions, funders, publishers, etc.).

Policy mandates were seen as fundamentally positive in encouraging change in this area as in others relating to $\mathrm{OA}$, but the pressures of trying to manage compliance with multiple funder policies which were sometimes seen as being in tension with each other (or at least, different in their emphases) was highlighted by many interviewees a major operational challenge. This created a complex picture:

"It's not uncommon to have more than one funder per project ... there will normally be at least two open access policies that apply; your funders, and HEFCE's because that applies potentially to everything ... They are sort of similar, in that they all want open access but they define this in slightly different ways." H-U.

The build-up of these policies was seen as an instrumental factor of the complexity termed as the, "the policy stack" by some participants. This was seen as particularly complicated by the collaborative nature of research and overlain by complexity associated with publisher policies:

"A lot of work is done collaboratively, cross-institutional, cross-national, sometimes with multiple funders, so you start getting a swirl of policies involved there. You've then got publishers who also have different policies and some publisher policies are different depending on where you got funded from." RG-EA.

The context then was seen to be one where there was a desire to create fundamental change in the scholarly communication system leading to greater openness, but where doing so was fraught with complexity. All of this overlay a culture within most academic disciplines where esteem was linked very clearly to publication in particular respected journals and where copyright was a sensitive issue on which the intervention of the institution was often not welcomed. Support services that serve researchers in institutions often found themselves undertaking tortuous processes in order to reconcile the differing demands of the involved stakeholders, which consequently had an impact on the overall engagement with open access by authors.

"At all of these meetings there was someone saying 'it's too complicated, it just takes too much work, the policies are too confusing and not helpful, can you just make this go away? Or if you can't make this go away, can you make it easier?". H-U.

Mandates were therefore seen as having the positive effect of encouraging OA but had created operational challenges for institutions and some amount of confusion amongst authors. It was in this context that the UK-SCL was seen to have a role.

The most commonly cited immediate driver for introducing the UK-SCL was the role it was expected to play in enabling compliance with "the policy stack". HEIs rely on often millions of pounds' worth of funding, and therefore wish to be able to ensure compliance with funder requirements. Participants felt that there was an increased institutional pressure to have high OA compliance rates to maintain funding: 
"Ultimately what the institution wants to know is that we are complying with that REF HEFCE policy so that anything we do produce we can potentially submit, and we're not at risk of losing funding from folks like RCUK if we are not complying with their rules." RG-EA.

Participants involved all felt that busy academics themselves should not feel over-burdened with navigating the policies and processes associated with compliance, but rather should be provided with straightforward solutions:

"It's practical; they're time-poor, you know, and this is another area of information that is bureaucratic, it's administrative, and they don't need to worry about it, you know they've got so many other agendas going on." RG-LA.

Importantly, the implementation of the UK-SCL's standard licence would not require any additional administrative work on the part of academics.

Linked to this, another driver of the UK-SCL was to attempt to constrain costs associated with compliance with mandates. The combination of funder requirements and publishers' extended embargo periods, currently often meant relying on hybrid gold journals, which were seen as costly:

"So if you have something that's MRC funded and it should be made open access within 6 months but the publisher only allows open access through the green route after 12 months then you have to publish hybrid. You're forced to pay an APC." RG-EA.

Payment of APCs for hybrid journals (which were seen as especially expensive) and the resulting perceived 'double dipping' by publishers came under particular criticism. The UK-SCL was seen as an alternative approach to maintaining high compliance rates, whilst at the same time facilitating a transition to sustainable open access, at which many OA funder and national policies were ultimately aiming. Some participants were keen to emphasise the need for the licence in the short-term, while the transition was occurring:

"We're presenting ... that this is a stop gap, that until we get to a point where we are in a different publishing environment where we haven't got hybrid, where we haven't got paywalls, and there's a different business model, this is how we want to do it ... It's taking the pain away during the transition, whatever that transition is." RG-EA.

However, once again there was concern over how this transition would be able to take place sustainably for institutions. This, most notably, was evidenced in the widespread anxiety over the continuation of the RCUK block grant, which primarily funds OA APC costs in institutions:

"... with the RCUK funding only initially guaranteed for 5 years. You know, there is no guarantee, none of us know what's going to happen beyond next April, and that's actually causing a particular challenge at the moment." RG-EA.

One key perspective of many participants was that many current problems with sustainability were actually the result of the failure of the planned 5-year transition period laid out in the Finch Report:

"When the Finch Report came out there was this notion of a five-year transition-well we're at the end of that now and it hasn't happened. So we want to put something in place that works now," RG-EA.

"Again, the funders always said this is supposed to be a transition period, a 5-year transition period, has there been a transition? Well no there hasn't. Are the funders going to do anything about it? No, they're going to say, here's a little bit less money, we are just going to make it awkward for everybody involved, we're gonna go on for another few years and we'll see." $\mathrm{H}-\mathrm{U}$.

The frustration evident in these comments was noticeable in many of the participants' interviews, and also helps to explain why the UK-SCL initiative has gathered momentum in the UK at this particular time. Measures put in place following the Finch Report in 2012, participants explained, had not resulted in the transition to a sustainable OA environment that had been anticipated. The UK-SCL was seen as a way of addressing some of the unsatisfactory and unintended consequences of the Finch Report recommendations. 


\subsection{What Are the Benefits and Challenges of Implementing the Licence?}

The UK-SCL was designed to address these key issues discussed by participants. In particular, they highlighted a number of benefits, including enabling compliance with mandates, assisting authors in maintaining control of their publications, cost savings for institutions, and earlier and wider dissemination of research. However, challenges were also highlighted by participants, in particular (mis)understandings amongst researchers, publisher resistance, and administrative demands.

As the immediate driver for this licence was enabling compliance, the most common benefit described initially was that it allowed 'one-step' compliance with various policies. Nearly all participants focused on the ability to meet multiple mandates simply and consistently:

"As an academic, if your institution has that type of licence, you mostly don't have to worry anymore about funder policies because as long as you deposit your manuscript with the institution, you will effectively meet all global open access funder requirements." H-U.

Participants also highlighted two key areas in which the licence could benefit authors by enabling them to retain control over their own work. Firstly, they would have immediate access to their own outputs for reuse in teaching and research:

"For the authors, I think it's the fact that they retain their rights to reuse their own work, for research and teaching. I think that's absolutely essential." Pre-92-LA.

Secondly, they would have the ability to retain the freedom to publish where they choose at the same time as meeting OA mandates:

"It contributes to preserving academic freedom to publish where academics like. I mention this particularly because publishers often use the argument that policies like those restrict academic freedom; I'd argue the exact opposite." H-U.

Many participants also felt it would lead to cost savings. The licence would enable immediate open access on publication through the green OA route, ensuring compliance with funders' policies; it can eliminate the reliance on hybrid journals:

"A big kind of benefit for this ... is hopefully moving away from hybrid open access and not having to pay APCs, because we take the embargoes out." RG-EA.

However, it was not only the direct cost savings that were cited but also the potential administrative efficiencies and improvements:

"... doing all the administrative and processing stuff and I think that's where it's a benefit to a service ... you can free up time for staff to actually do more engagement perhaps, more advocacy around open access and open scholarship." Pre-92-LA.

Open access and open scholarship in general were seen to benefit. Participants emphasised the potential for disseminating material earlier (with the removal of the effect of embargoes), and more widely (with open access as the default for all outputs). Greater visibility for researchers' outputs would result in broader research benefits:

"It will increase the amount of open access material undoubtedly, because it takes the decision, and the processing of open access material out of the hands of the individual academics." H-U.

However, as well as emphasising the anticipated benefits, participants gave equal room to discussing the challenges of implementation, including the possible perceptions of the policy as a complication instead of simplification. An aspect of this response centred on the copyright and IPR:

"So academics [are] not really understanding what the point of this licence is and not really understanding what difference it makes to their rights." RG-LA. 
This again might prove to be particularly challenging due to the ongoing inconsistency between policy and practice surrounding rights, as one participant mentioned:

"At some point, policy is going to clash with practice and we'll have academics wondering what on earth's going on, who probably aren't at all clear what the [institutional] IP Policy says, even though they've said they've signed it and read it." RG-EA.

Some participants mentioned possible wider objections around academic freedom, particularly from authors who might believe they were "losing out on the ability to sign with a publisher of their choice" (Pre-92-LA). Interviewees were keen to stress that the UK-SCL would not be operated in such a way as to be seen to putting barriers in the way of researchers publishing their results. This would necessitate waivers to the licence being granted:

"... the university will grant waivers because we respect that an academic might have different views and we don't want to make the academic publishing process more painful and difficult than it already is where possible." H-U.

However, such an approach had the potential to create problems with the relationship with publishers associated with UK-SCL implementation-a major cause for concern. Whilst many participants said they only intended to operate waivers in exceptional circumstances (for authors, "if they really, really, really insist on it, or if their publisher really, really insists on it", (RG-LA), it was, however, recognised there may be "pushback" from publishers, who may demand 'mass waivers', which would negate the impact of the licence:

"There is a risk that the publishers will just say 'well, we want a waiver for all of our stuff'." H-U.

Participants were conscious that a balance would need to be achieved on this issue-creating significant change, which might involve some amount of disruption, on the one hand, whilst still enabling publishing of outputs from the institution to continue to take place smoothly. There was an unresolved tension here underlying many of the views of participants: to some extent there was an acceptance that the UK-SCL would create some kind of 'crunch point' with publishers (in many respects that was integral to the initiative), but that created risks. The fear was expressed by some participants that the working relationship between the publisher and the institution would somehow be jeopardised, and therefore disadvantage the institution's academics. This would need careful handling.

There was a consciousness that communication with institutional authors to explain the benefits of the UK-SCL was crucial, particularly as publishers were well able to engage directly with authors themselves:

"They have databases full of names of authors, they can contact our staff directly because our staff effectively work for them. They're editors, they're peer-reviewers, they're authors ... there's a risk that they could try to engender support for their own cause from our own staff." RG-EA.

Several of the participants highlighted the relationship dynamics between authors, publishers and the institution, noting that the often-close relationships between author and their preferred journals would need to be taken into account when communicating information about the UK-SCL. Participants were aware that there could be potential for creating tension between institution and publisher, with the UK-SCL being seen as getting in the middle of a long-established author-publisher relationship. This highlighted the need for clear and consistent communication about the rationale for and likely impacts of the licence.

Quite apart from communication priorities, developing a new policy and seeing it through to implementation was also seen to be a heavy burden, and increased workload was seen as a third potential challenge. One participant especially felt that this may be too much for their service:

"In the library we are slightly concerned that administering the UK-SCL will put additional burden on an already very overstretched team." Pre-92-LA. 
However, overall, there was a generally optimism that although it probably will cause an increase in work, during a 'bedding-in period', it should simplify workflows in the long-term:

"I think initially it is probably going to be more work but I'm hoping that eventually it will be less work." H-U.

The double-sided nature of many of these remarks is notable-benefits of easy compliance and greater control for academics also has the potential to be complicated and confusing for them; and the benefit of service efficiency and sustainability for the library could also become an added administrative burden, at least initially.

\subsection{How Is the Policy Being Adopted?}

All participants were at different implementation stages, giving a wide variety of views on how the UK-SCL in initiative was developing in practice. The main factors influencing decisions regarding implementation of the policy were believed to include institutional collaborations, external support, internal communication and engagement, legal complexities, the development of business processes, and the library's position within the wider institution.

Collaboration between institutions was seen as key. It was believed that implementation would be easier and far more successful if it involved a critical mass of institutions, by sharing risk and increasing their collective power:

"There's safety in numbers isn't there? ... We didn't want to do it individually because it's easier for us to get picked off by people who didn't support us." RG-EA.

"The more institutions that adopt this, the better it will be and the more persuasive we can be on the issue." RG-EA.

As well as looking for support from a growing number of institutions, it was seen as vital for the project partners in HEIs to gain external support from other organisations, particularly funding bodies:

"RLUK have been supportive in offering an endorsement... its useful to have big sector bodies essentially endorsing this or supporting this because I suppose it's validates what you are trying to do and what you are trying to achieve." RG-EA.

"It's not just something thought up, it's actually grounded, it's got all the authority that it requires. So I think that will help, absolutely." P1-EA.

As well as securing strong support from partners, institutions were also focusing on achieving internal buy-in through tailored communications. Ensuring approval from university-level governance bodies for the licence was seen as a particular priority. Many participants felt it was also important to ensure clear understanding of the licence amongst key individuals, prior to meetings, to ensure buy-in:

"... get that buy-in as early as possible from both ways-from the ground-up and the top-down and you know it should be a matter of pushing it out there, confirming it and then putting it through the various committees without too many obstacles." RG-LA.

Another approach was to leverage the examples of others taking up the UK-SCL as a further incentive for implementing the licence:

"All it will take I can imagine is at Research Committee saying, 'well this has been adopted by [Institution name]', I think that will immediately have an impact." Pre-92-LA.

This response is indicative of the interesting tension at play between collaboration and competition between institutions. Competition could potentially become a secondary driver, if institutions feel they are being left out of a group doing something innovative, they may be encouraged to adopt the licence. 
It was emphasised that communications with academic staff, as well as senior managers, also needed to be tailored. It was felt by some that the best way to communicate the benefits of the licence was for the message to come from academic advocates, rather than library (or other professional services) staff:

"The most effective way is through their peers ... to spread the message as well as it coming down through the website, through emails. The website, which people aren't going to read, the emails, which people are going to throw away, the conversation over coffee in the SCR, yeah they're more likely to remember that." H-U.

Persuasion of key academics who could then become 'champions' was seen as crucial. Throughout, those expecting to adopt the licence focused on involving all stakeholders in the process, and participants were at pains to emphasise this was true of communications with publishers as well:

"We are doing our best to reach out to the publishing community to answer all their questions, as we did when we met, when they brought a string of questions to us." RG-EA.

The importance of publisher communications was also emphasised as a way of attempting to clarify legal questions around the licence, particularly around the status of the UK-SCL as a prior licence which would 'trump' any subsequent licences signed by authors. Therefore, participants were taking this into consideration:

"... a formal communication to say 'this is what we're doing' and we know that the legal status of the licence as trumping any copyright assignments relies upon the publishers not being able to say they couldn't reasonably have known about it. So there has to be a big bang." RG-EA.

Another legal issue around the adoption of the licence was its relationship with an institution's established IP policy. Accounting for this was generally taking the form of either making an alteration to the institutional policy itself or, less commonly, a change to employee's contracts:

"It needs to dovetail in with your institutional IP policy. So the two can't say contradictory things ... Some contracts of employment specifically have the policies in the contract, others refer to the policies and then say something like 'thou shall abide by policies, which from time to time may change'." RG-EA.

Whilst many participants focused on broader policy positions, others emphasised that they had planned the detail of the workflows that would come from UK-SCL adoption. At this stage of the implementation some had progressed further than others. One participant was particularly keen to demonstrate the potential ease of depositing research outputs under the licence:

"The simple example is there's one academic at an institution writing an article, the publisher is not asking for a waiver, then it's extremely easy because the academic deposits ... the university ... simply adds the correct licence, makes the output available when it's published and case closed." $\mathrm{H}-\mathrm{U}$.

However, it was clear that arrangements for setting up more complex processes, such as getting co-author agreements from non-participating institutions, were still being discussed:

"We are thinking about how authors need to gain permission from any co-authors ... There's looking at research collaboration agreements, essentially the contracts that are signed between the institutions ... but also within any sort of co-author permission requests, how can we try and attempt to make our academics' life a bit easier by providing standard texts that they can use." RG-EA.

At the centre of the discussions in their respective institutions were senior members of staff from the library service. Library research support has developed over recent years and their ability to lead on the UK-SCL arguably indicates that their OA services are maturing. Multiple participants pointed to their strong OA infrastructure and support arrangements when discussing their involvement in this initiative: 
"We have done an awful lot in terms of providing support to researchers, so currently we've got a research data manager, we've got a repository obviously, we set up a repository years ago, so we're doing a lot in terms of open access, we've got the mandate." Pre-92-EA.

However, the data also shows that it was those institutions whose OA infrastructure is well-developed and resourced who were generally expected to be first-adopters, and those with less well-developed services were more likely to be planning to implement later:

"Given our very weak open access infrastructure here, I think it would have been quite high-risk for us to be in that first cohort. I mean we haven't even got a research management system." Pre-92-LA.

The level of the maturity of the OA-related support services provided by the library, also seems to have been linked to how the library is perceived within the university as a whole. Many participants felt the library was becoming more embedded within the institution, forming stronger relationships with other services and departments:

"We have worked very hard over the last few years to be seen as peers, and partners, not as a 'support service' and we have worked very hard to get ourselves into the lifeblood of the institution." RG-EA.

Working with stakeholders such as the institution's Vice President or Pro-Vice-Chancellor for Research was seen as crucial in order to show institutional support for the project. Although driven by the library, it was clear that all participants were keen that the UK-SCL was not seen specifically as 'a library thing':

"I would hope that it's not seen as 'the library'. We're making it quite clear that this is a university thing, the library is co-ordinating the activity, but ... we have university approval for this." RG-EA.

On the other hand, a number of participants emphasised that they wanted the library to be seen as the part of the institution that was providing solutions for the institution as a whole. The UK-SCL was seen as a solution for the institution to significant current challenges in making open access a reality.

\section{Discussion}

Although the UK Scholarly Communication Licence is in many respects a recent iteration of a long-standing tradition of attempting to address open-access challenges through copyright management, it has emerged as an initiative in the UK at this time for specific contingent reasons which were apparent in the data collected for this study. The UK-SCL initiative is to a large extent born out of frustration with the UK post-Finch policy environment in which the anticipated transition to OA had not occurred as expected. This frustration has been expressed by Fyfe et al. as part of their analysis of the publishing market [39], and it has also been pointed out that the Finch Report recommendations were always an attempt to achieve two major objectives which were arguably in tension: both accelerating OA in a way that delivers value for money, whilst at the same time protecting the UK publishing industry [83]. This tension has been reflected in the ways in which OA has been achieved to date in the UK: with an emphasis on gold OA, delivered predominantly through hybrid journals [7,8]. In the absence of any cost-neutral offsetting, this approach has had the effect of adding further cost (in the form of APCs) to a sector already experiencing rising costs (of subscriptions) $[7,8]$. At the same time, effecting green OA has been made more difficult (despite growing levels of deposits in response to the REF mandate) by embargoes, which place tight constraints on when and how deposited items can be made openly available [8].

The UK-SCL initiative has developed as a response to these pressures and crucially has been driven by institutions, rather than national agencies, where the pressures of the current situation have been felt most keenly, prompting them to take action independently [84]. From an institutional point of view, the challenges around implementing OA have become complex and costly, making it difficult 
for them to design services and processes which enable them to achieve greater open access in an affordable way whilst concurrently satisfying the terms of different mandates [1,3]. The environment is seen as confusing to authors, with institutions and their libraries finding it difficult to give authors simple messages about how to adopt OA practices. Funder mandates in particular were seen by participants in this research to be focused on enforcing compliance without effectively addressing challenges around author behavioural incentives (particularly around journal impact factor-related esteem), which currently militate against adoption of OA practices $[40,85]$. The UK-SCL is in many respects a bold attempt to cut through these complexities by achieving greater simplicity and clarity for institutions through a focus on pre-emptive rights retention. Such an approach is not without risk, however, and involves institutions trying to manage the tension between, on the one hand, creating meaningful change (which is likely to involve disruption), whilst, on the other hand, enabling their researchers to participate in their subject communities by publishing their research results without restrictions. The response of publishers remains a major risk for the initiative.

At the centre of UK-SCL discussions in all institutions are their libraries. Libraries have achieved the position in many HEIs of being seen as the natural place to initiate and coordinate such initiatives, as part of a wider set of activities around scholarly communication [53,56,61,62]. It is clear, however, that the ability of libraries to lead in this way, does vary from institution to institution, and even where the library has gained support for its proposals in relevant governance groups (itself a challenge), there remains considerable advocacy work to do in the institution as a whole. The UK-SCL is itself, however, seen by some as a vehicle for more general advocacy about OA. The issues raised by the initiative in many ways encapsulate some of the key issues associated with OA implementation more generally, and it can therefore become a useful focus for discussion and debate. The controversial nature of the some of the issues raised, whilst challenging to tackle, may help to increase awareness, both in the UK and beyond.

Figure 1 maps out the key issues and relationships at play in the UK-SCL initiative that this research has brought into focus. It models the interactions between actors from the perspective of institutions implementing the UK-SCL, whose relationships with both funders and publishers, as well as other stakeholders are designed to be impacted by the UK-SCL. Firstly, the varying OA policies of different funders are shown in relation to the institution. The recent advent of UKRI, subsuming the Research Councils and the research functions of HEFCE, including the REF, is indicated. Within the institution, there a number of stakeholders, comprising academic faculties and professional support services as well as senior managers (such as Pro-Vice-Chancellors). Within the faculties of the institution are the producers and consumers of academic content (staff and students). These institutional actors all relate to each other in terms of the UK-SCL, with the library depicted separately to show its coordinating role in the initiative. Plans for the UK-SCL (its, as yet, unimplemented status indicated by dotted lines) are shown, and these relate in particular to publishers. There are several modes of formal interaction between the institution and publishers: exchange of content, payment of subscriptions and APCs, and imposition of embargoes - the UK-SCL adds to this list. Content is submitted by authors in the institution to publishers and acquired by the institution from publishers. Payments are made by the institution to publishers in the form of APCs (for OA publishers) and subscriptions and APCs (for other publishers), the later including APC payments for hybrid journals. At the same time, publishers' licences may often involve the institution adhering to embargoes on Green OA content. The figure indicates the areas where the UK-SCL has been designed to impact, particularly in the relationship with publishers, with regard to embargoes and hybrid charges, but also in the ability of HEIs to comply with funder mandates. The significance of the UK-SCL is illustrated by the fact that it is expected to affect such a wide range of important areas, and this in itself is indicative of why implementing such an apparently simple measure is quite so complex and controversial. A number of other stakeholders relating to HEIs, funders and publishers are also shown as illustrative of the wider environment (UUK, Jisc, RLUK etc.). Although these agencies relate to HEIs and will have positions on the UK-SCL, the 
UK-SCL itself is shown to have been generated as part of an institution-level initiative-a partnership of institutions, rather than any national agency.

The immediate future of the UK-SCL remains uncertain. Its launch has been delayed on more than one occasion and the final shape of its implementation, in terms of numbers of partners and the precise details of the licence terms, still need to be finalised. For instance, there have been more recent discussion about adding in an additional non-derivative clause to licence in some circumstances, which has been as a result of further work with their user community, particularly from the Arts and Social Sciences disciplines. Significantly, just as the initial impetus for the UK-SCL clearly came from the specifics of the UK scholarly communication environment, the reasons its launch has been held back owe a great deal to the changing UK situation. In April 2018, the governance structure of HE in the UK was overhauled, with the Research Councils and the research functions of HEFCE (including the REF) being subsumed into UKRI [86] (as Figure 1 shows). The gold-centric approach to date favoured by Research Councils UK and the green-centric approach favoured by HEFCE for the REF, are now being reviewed along with evidence of the impact of those policies, particularly since the Finch Report in 2012, and other international developments [87]. In this context, the plans for the UK-SCL are clearly something that need to be taken into account. Whilst the UK-SCL has been developed outside of policy environment of funding agencies, plans for its implementation have become a feature of the current landscape that now need to be considered by policy makers. Jisc (which manages network and digital content services for UK HE), in a report written to contribute to the UK policy review, has recommended "support for institutional IPR policies that facilitate the transition to open access" in the UK, the UK-SCL could reasonably be considered to a relevant initiative in this area [88].

This developing policy environment needs to be carefully monitored and new evidence-based contributions to the discussion encouraged. This current study has highlighted attitudes and motivations in HEIs, which are an important part of the landscape. Of course, the study has been limited to those who have instigated and driven the development of the UK-SCL, and further work would now be useful to evaluate the views of other stakeholders in institutions (such as researchers from different disciplines, research support professionals and senior managers) as well as others outside HEIs, particularly publishers and funders. Crucially, when the licence is launched or developments underpinned by similar principles are implemented, their impact will need to be carefully studied. This would help in developing an understanding of how the UK-SCL, or initiatives like it, might play a role in the scholarly communication environment of the future. 


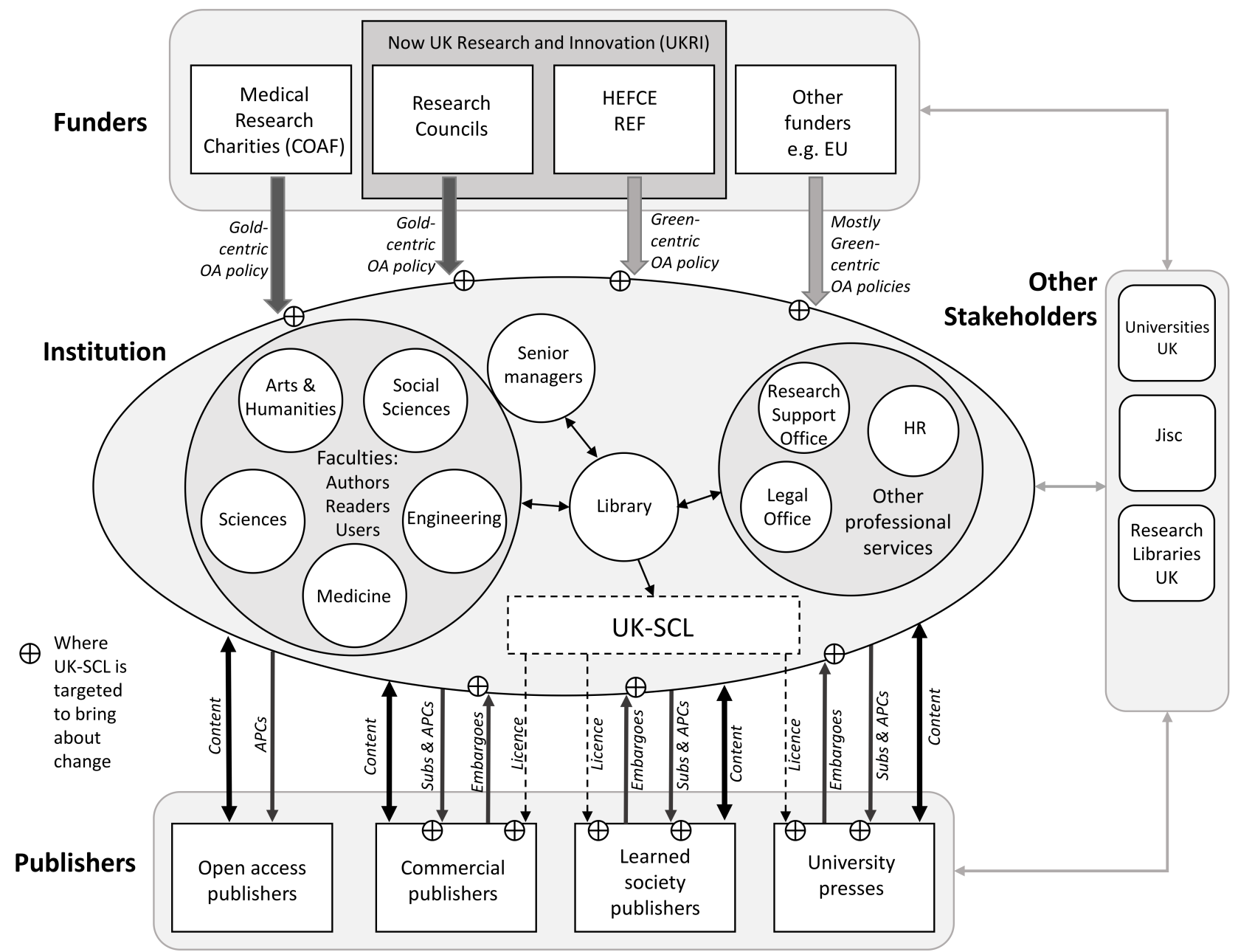

Figure 1. Key stakeholders and relationships involved in the United Kingdom Scholarly Communication Licence (UK-SCL) implementation from a higher education institution perspective. 


\section{Conclusions}

The idea behind the UK-SCL initiative is a simple one. It attempts to cut through the 'Gordian knot' of complexities of funders' mandates, publishers' policies, and researchers' caution in one single policy with the aim of achieving greater open access. This research has highlighted the circumstances within the UK which have given rise to the initiative, and which has enabled it to gain significant support in higher education institutions. It is part of a concerted effort to shift the current UK landscape towards a fuller transition to openness, a transition which many stakeholders in HEIs believe has become stuck. The UK-SCL has been designed to unstick the situation, or at least contribute to doing so. However, whilst the idea behind the policy is a simple one, bringing any kind of large-scale, potentially disruptive change to this highly complex environment has proved to be difficult and controversial. With the review of UK open access policy underway in 2018, it will be interesting to see what role this type of development could play in the future policy landscape both in the UK and beyond.

Author Contributions: Conceptualisation, J.B. and S.P.; Methodology, J.B. and S.P.; Formal Analysis, J.B.; Investigation, J.B.; Data Curation, J.B.; Writing-Original Draft Preparation, J.B.; Writing-Review and Editing, S.P. and J.B.; Project administration, J.B. and S.P.

Funding: This research received no external funding.

Declaration of Interest: Stephen Pinfield was founding director of SHERPA between 2002 and 2012. He currently acts as external adviser to SHERPA.

\section{Appendix A. UK Scholarly Communications Licence and Policy Interview Schedule}

1. Please can you explain your institution's approach to the implementation of the UK Scholarly Communications Licence and where you are currently in this implementation process?

2. Why has your institution decided upon this particular approach to the UK-SCL?

3. What benefits do you anticipate the UK-SCL will bring to your institution and scholarly communications as a whole?

4. From your prior knowledge and experience so far, what do you foresee as the possible challenges the UK-SCL may cause?

5. What are the practicalities which must be taken into account?

6. To what extent has this initiative been driven by the library rather than the university?

7. Has your institution been working collaboratively with other institutions or organisations and how has this worked so far?

8. What do you believe will be the short and long-term consequences of your institutions implementation of this?

\section{Appendix B. Draft UK-SCL Licence and Model Policy}

\section{UK Scholarly Communications Licence and Model Policy v1 (09/11/2017)}

1. Why a model open access policy is needed in the UK

There are three drivers:

- Works that are available open access typically receive more citations than equivalent works available only through publisher subscriptions.

- Peer reviewed journal articles and conference proceedings written by UK research academics are covered by numerous policies. Funder policies typically give minimum compliance requirements and are increasingly encouraging researchers to go beyond those. Funder policies are not yet aligned making funder compliance and REF eligibility complex. Publishers, too, have different policies, some of which vary depending on the funding received by the researcher. We've called this the "policy stack". 
- This "policy stack" is complex for academics to navigate and administratively complex to manage.

The UK-SCL is a model policy and licence intended to support authors. It can be implemented by universities and, through a single deposit action, ensures the academic retention of re-use rights, compliance with the deposit requirements of most major research funders and eligibility for submission of outputs to the REF2021 exercise. It allows authors to reuse their own content, for example in teaching and future scholarship. The UK-SCL has been drawn up with the aim of being reasonable to authors, funders and publishers, whilst preserving the academic freedom to publish in the journal of their choice. It is not intended to undermine the publishing process and all the benefits that that brings, including, as is in widespread use currently, peer-review, esteem, promotion and career progression. The UK-SCL is seen as an interim solution ${ }^{\mathrm{i}}$ to help authors make their outputs available as open access and meet funder requirements until sustainable open access publishing models emerge.

In particular, the licence supports researchers by:

- Enabling the timely communication of the findings of publicly-funded research (thereby increasing citations and impact);

- Supporting academics in meeting funder requirements for open access whilst preserving the right to publish in the journal of choice;

- Allowing academics to retain (C) in their outputs and, if required by the publisher, to assign (C) to the publisher;

- Through the automatic granting of a licence, allowing the reuse of research outputs, for example for research and teaching;

- Allowing the accepted manuscript to be made available in digital repositories;

- Enabling compliance with multiple funder policies and REF2021 eligibility through a single action.

2. Key elements of the UK-SCL

Under the UK-SCL, research institutions implement local policies which ensure the retention of re-use rights through a non-exclusive licence in author accepted manuscripts of scholarly articles written by their staff (all individuals employed by the university who publish scholarly outputs). The licence is non-exclusive so that the final version of record can still be published through a journal in the same way as before. No legal agreement with the publisher is required and there is no need for authors to sign or modify any paperwork or take any other action for the licence to apply.

The licence allows the institution to make the peer-reviewed manuscript of the article publicly available (usually through its repository) following publication of the version of record by the publisher (or earlier if the publisher's own policy allows). Manuscripts will be available under the widely-used Creative Commons licence CC BY NC (4.0), allowing non-commercial reuse with the proviso that the author(s) always have to be credited. This licence meets funder requirements for open access, e.g., for RCUK and Horizon2020 funded research as well as ensuring eligibility of the outputs for REF2021. Copyright, and, by extension, moral rights, are retained by the author.

The institution automatically sublicenses all authors and institutions credited on the paper to do the same. This means authors can re-use their author accepted manuscript for teaching and research, and they can share it widely on platforms of their choice.

If an author is concerned about the author accepted manuscript being made available they can request the institution to waive the rights for a certain period (waiver; see below).

3. Institutional implementation

Research institutions implement the UK-SCL through their own policies and processes, in-line with established institutional practice and culture. To be considered to have implemented the UK-SCL, an institutional policy needs to include the following conditions: 
(1) Retain the right to make accepted manuscripts of scholarly articles authored by its staff available publicly under the CC BY NC (4.0) licence from the moment of first publication (or earlier if the publisher's policy allows).

(2) Allow authors and publishers to request a temporary waiver for applying this right for up to 12 months for AHSS and 6 months for STEM (aligned to REF panels).

(3) Where a paper is co-authored with external co-authors, the institution will:

a. Automatically sublicense this right to all co-authors credited on the paper and to their host institutions.

b. Not apply the licence if a co-author (who is not based at an institution with a UK-SCL-based model policy) objects.

c. Honour waiver requests granted by other institutions which have adopted the UK-SCL model policy.

4. Implication for authors

(1) Papers with a single author or co-authors based at UK-SCL institutions:

- There is no additional action required as far as their institution is concerned.

- A publisher may request a waiver (see above) in order to publish the output. The institutions will make a simple workflow available to meet these requests. During an implementation and trial phase, initially for 2018 and 2019, institutions will issue blanket waivers for all publishers who request them, so that authors do not have to take action. This approach will be negotiated and managed centrally and will be reviewed annually.

(2) Papers with co-authors at institutions who have not implemented the UK-SCL:

- Co-author consent for the UK-SCL to apply can be managed using existing mechanisms for managing journal selection, copyright assignment and institutional repository deposit. Institutions will provide simple boiler-plate text to facilitate this process, and will seek to add a relevant clause to research collaboration agreements to facilitate this process in the future. Co-authors need to give their consent for the UK-SCL to apply. This can be managed by what is called 'estoppel', i.e., corresponding authors informing their co-authors and taking silence as consent. Institutions will provide simple boiler-plate text to facilitate this process, and will seek to add a relevant clause to research collaboration agreements to facilitate this process in the future.

- During the early implementation of the policy the institution will support the communications with co-authors by seeking consent from co-authors on behalf of staff, by supporting staff through the provision of boilerplate text, or will not require staff to ask co $\neg$ authors for consent (\& consequently not deposit under the terms of the UK-SCL).

(3) Authors who use content (such as images) with third party rights in their articles:

- The same rules apply as for any deposit in an open access repository: authors are either able to secure the rights to reproduce the content under the licence used by the repository, or to note the elements of the manuscript that are to be made available with a rights reserved statement.

(4) Authors who publish open access already:

- Where an article is published under a CC BY licence by the publisher, the institution will use the open access version of record from the publisher and not the accepted manuscript (which will remain under closed access in the repository). 
5. Model policy ${ }^{\mathrm{ii}}$ To help institutions with implementation of the UK-SCL this model policy is provided to guide local implementation.

(1) (University name) is committed to disseminating its research and scholarship as widely as possible. It supports the principle that the results of research should be freely accessible to the public. To enable staffiii to publish their work in a journal of their choice and still meet funder requirements for open access, (university name) adopts the following policy:

(2) Each staff member grants to (university name) a non-exclusive, irrevocable, sub-licensable, worldwide non-commercial licence to make manuscripts of his or her scholarly articles publicly available. This licence is granted on condition that, if (university name) does make the said scholarly articles available, it will only do so on the terms of a Creative Commons Attribution Non-Commercial v4 (CC BY NC) licence.

(3) The licence applies to all scholarly articles (including conference proceedings) authored or co-authored while the person is a staff member of (university name) including any third party content where rights in that content have been secured (all for the purposes of this policy "articles") except for any articles submitted before the adoption of this policy and any articles for which the staff member entered into an incompatible licensing or assignment agreement before the adoption of this policy. It does not apply to monographs, scholarly editions, text books, book chapters, collections of essays, datasets, or other outputs that are not scholarly articles. Upon express and timely ${ }^{\mathrm{iv}}$ direction by a staff member, the (Provost) ${ }^{\mathrm{v}}$ or (Provost's) designate will give every consideration ${ }^{\mathrm{vi}}$ to a waiver of the terms of the licence and allow a delay in the public release of the manuscript for a period of up to twelve months from the date of first publication (embargo).

(4) Where this policy applies to an article that is co-authored, the staff member will use all reasonable endeavours to obtain a licence to (university name) from all the co-authors on the same terms as the licence granted under this policy by the staff member. (university name) automatically sub-licenses the rights granted to it under this policy to all co-authors and their host institutions, on condition that if the said co-authors and/or host institutions make a co-authored scholarly article publicly available, they will do so on the terms of a CC BY NC licence. Consequently, the staff member need not seek permission from co-authors employed by institutions that have adopted this policy or other policies that give institutions and/or authors the same rights.

(5) Each staff member will provide an electronic copy of the accepted manuscriptvii (AM) of each article at no charge to the appropriate representative of the (Provost's) Office in an appropriate format (such as PDF) specified by the (Provost's) Office. (university name) will deposit the AM in a digital repository, with article metadata usually available immediately upon deposit and the AM being made accessible to the public on the date of first publication (online $e^{\text {viii }}$ or otherwise) under a Creative Commons Attribution Non-Commercial (CC BY NC) licence except where the version of record is published open access and with a Creative Commons Attribution (CC BY) licence, in which case the AM will remain on closed deposit. Deposit of other types of scholarly outputs is encouraged but neither required nor included in the licence grant.

(6) Staff members will, when providing the electronic copy of the AM, notify the (Provost's) Office if any rights or permissions needed to make third party or co-authored content in an article publicly available under a CC BY NC licence have not been secured and which consequently need to be made available with a rights reserved statement.

(7) The (Provost's) Office will be responsible for interpreting this policy, resolving disputes concerning application, and recommending changes. The (Provost's) Office shall use all reasonable endeavours to inform publishers and relevant agents of the existence and contents of this policy. The policy will be reviewed annually. 
Notes

i. Interim solution: It remains to be seen how long this policy will remain necessary or appropriate. It may evolve over time following periodic review. For example, under a pure open access publishing model the policy would no longer be necessary.

ii. This model policy is based on the Harvard Model Open Access Policy-https:/ / osc.hul.harvar d.edu/modelpolicy / (accessed on 22 September 2017) with adjustments to take account of the UK legal framework.

iii. Staff: The wording here applies to all individuals employed by the university, whether research active or not, who publish scholarly outputs, including students who are considered as "employees" by an institution, and any other persons who have agreed that this policy applies to them by virtue of the terms on which they are engaged by the university or are given access to the facilities and resources of the university.

iv. Timely: Once the output is made public in the repository the Creative Commons licence cannot be changed retrospectively. Staff should request a waiver at acceptance.

v. "Provost" may be replaced with "President", "Principal", "Vice Chancellor" etc. as appropriate.

vi. Every consideration: The waiver addresses concerns authors may have regarding the policy. These include concerns about academic freedom, freedom to accommodate publisher policies, external co-authors with objections to immediate open access, and the like. The university will generally grant waivers but reserves the right to define criteria for conditions under which waiver requests will not be granted (for example when a waiver would put the university under risk of non-compliance with a funder policy).

vii. Accepted manuscript: The peer-reviewed version of an article that has been accepted for publication in a journal or conference proceeding. The accepted manuscript is not the same as the typeset or published paper. The Funding Councils require deposit of the accepted manuscript to make an output eligible for the REF. NISO definition: http:/ /www.niso.org/p ublications/rp/RP-8-2008.pdf (accessed on 1 September 2017). HEFCE: http:/ /www.hefce.ac .uk/rsrch/oa/faq/\#deposit4 (accessed on 1 September 2017).

viii. First publication: This policy is intended to align with the HEFCE definition of first publication outlined in Section 4.5 of the HEFCE FAQ http:/ / www.hefce.ac.uk/rsrch/oa/faq/ (accessed on 13 October 2017).

\section{References}

1. Banks, C. Focusing upstream: Supporting scholarly communication by academics. Insights 2016, $29,37-44$. [CrossRef]

2. Making Open Access Work for Authors, Institutions and Publishers: A Report on an Open Access Roundtable Hosted by the Copyright Clearance Center Inc. Available online: http:/ / www.copyright.com/content/da m/cc3/marketing/documents/pdfs/Report-Making-Open-Access-Work.pdf (accessed on 23 March 2017).

3. Fruin, C. Organization and Delivery of Scholarly Communications Services by Academic and Research Libraries in the United Kingdom: Observations from Across the Pond. J. Libr. Sch. Commun. 2017, 5, 2157. [CrossRef]

4. DeGroff, H. Preparing for the Research Excellence Framework: Examples of Open Access Good Practice across the United Kingdom. Ser. Libr. 2016, 71, 96-111. [CrossRef]

5. Finch, J. Accessibility, sustainability, excellence: How to expand access to research publications. Report of the Working Group on Expanding Access to Published Research Findings-The Finch Group. 2012. Available online: http:/ / www.researchinfonet.org/publish/finch/ (accessed on 5 August 2017).

6. Higher Education Funding Council for England (HEFCE). Policy for Open Access in the Next Research Excellence Framework; Higher Education Funding Council for England: London, UK, 2016; Available online: http:/ / www.hefce.ac.uk/pubs/year/2016/201635/ (accessed on 24 February 2017). 
7. Jubb, M.; Goldstein, S.; Amin, M.; Plume, A.; Aisati, M.; Oeben, S.; Pinfield, S.; Bath, P.A.; Salter, J.; Johnson, R.; et al. Monitoring the Transition to Open Access: A Report for Universities UK; Universities UK: London, UK, 2015; Available online: http:/ / www.researchinfonet.org/oamonitoring/ (accessed on 12 February 2017).

8. Jubb, M.; Plume, A.; Oeben, S.; Brammer, L.; Johnson, R.; Bütün, C.; Pinfield, S. Monitoring the Transition to Open Access; Universities UK: London, UK, 2017; Available online: http:/ /www.universitiesuk.ac.uk/policyand-analysis/reports/Pages/monitoring-transition-open-access-2017.aspx (accessed on 29 January 2018).

9. Pinfield, S.; Salter, J.; Bath, P.A. The "total cost of publication" in a hybrid open-access environment: Institutional approaches to funding journal article-processing charges in combination with subscriptions. J. Assoc. Inf. Sci. Technol. 2016, 67, 1751-1766. [CrossRef]

10. Pinfield, S.; Salter, J.; Bath, P.A. A “gold-centric" implementation of open access: Hybrid journals, the "total cost of publication", and policy development in the UK and beyond. J. Assoc. Inf. Sci. Technol. 2017, 68, 2248-2263. [CrossRef]

11. Sutton, S.C. Open access, publisher embargoes, and the voluntary nature of scholarship: An analysis. Coll. Res. Libr. News 2013, 74, 468-472. Available online: https://crln.acrl.org/index.php/crlnews/article/vi ew/9008/9804 (accessed on 12 February 2017). [CrossRef]

12. Gadd, E.; Troll Covey, D. What does 'green' open access mean? Tracking twelve years of changes to journal publisher self-archiving policies. J. Librariansh. Inf. Sci. 2016. [CrossRef]

13. Björk, B.C. Scholarly journal publishing in transition-from restricted to open access. Electron. Mark. 2017, 27, 101-109. [CrossRef]

14. Reimer, T. The UK Scholarly Communications Licence-Supporting academics with open access. ALISS Q. 2017, 12, 3-5. [CrossRef]

15. Harvard Library. Open Access Policies. Available online: https://osc.hul.harvard.edu/policies/ (accessed on 24 April 2017).

16. Carter, I. Executive Summary of Business for Research and Knowledge Exchange Committee: UK Scholarly Communications Licence. 2016. Available online: https://www.sussex.ac.uk/webteam/gateway/file.php? name=rkec-34-05-uk-scholarly-communications-licence.pdfandsite=22 (accessed on 10 February 2017).

17. UK-SCL. UK Scholarly Communications Licence and Model Policy. Available online: http://UK-SCL.ac.uk/ (accessed on 3 January 2018).

18. Reimer, T. The UK Scholarly Communications Licence-A model for (open access) rights retention. In Proceedings of the 106th German Library Congress, Frankfurt/Main, Germany, 30 May 2017; Available online: https:/ / zenodo.org/record/153928/files/Reimer_UKSCL_OAT2016.pdf (accessed on 12 December 2017).

19. Willinsky, J. Copyright contradictions in scholarly publishing. First Monday 2002, 7. [CrossRef]

20. Ober, J. Facilitating open access: Developing support for author control of copyright. Coll. Res. Libr. News 2006, 67, 219-255. [CrossRef]

21. Suber, P. Open Access [online]; MIT Press: Boston, MA, USA, 2012; Available online: http:/ / mitpress.mit.edu /books / open-access (accessed on 21 February 2017).

22. Wulf, K.; Newman, S. Missing the Target: The UK Scholarly Communications License. Available online: https:/ / scholarlykitchen.sspnet.org/2017/07/26/missing-target-uk-scholarly-communications-license/ (accessed on 1 August 2017).

23. Lewis, D.W. The inevitability of open access. Coll. Res. Libr. 2012, 73, 493-506. [CrossRef]

24. Clobridge, A. Open access: Progress, possibilities, and the changing scholarly communications ecosystem. Online Search. Inf. Discov. Technol Strateg. 2014, 38, 1-15.

25. Pinfield, S. Making open access work: The "state-of-the-art" in providing Open Access to scholarly literature. Online Inf. Rev. 2015, 39, 604-636. [CrossRef]

26. Eve, M.P. Open Access and the Humanities; Cambridge Books Online; Cambridge University Press: Cambridge, UK, 2014; Available online: https:/ /hcommons.org/deposits/download/mla:290/CONTENT/9781107097 896ar.pdf/ (accessed on 5 May 2017).

27. Ayris, P.; McLaren, E.; Moyle, M.; Sharp, C.; Speicher, L. Open Access in UCL: A new paradigm for London's global university in research support. Aust. Acad. Res. Libr. 2014, 45, 282-295. [CrossRef]

28. Kingsley, D.A. Paying for publication: Issues and challenges for research support services. Aust. Acad. Res. Libr. 2014, 45, 262-281. [CrossRef] 
29. Cooke, J.; Clarkson, N.; Kerridge, S.; McCutcheon, V.; Tripp, L.; Walker, K.; Waller, C. Open Access and the REF: Issues and Potential Solutions Workshop: Executive Summary. 2015. Available online: http:/ / eprints.gla.ac.uk/104395/1/104395.pdf (accessed on 12 August 2017).

30. RCUK. RCUK Policy on Open Access and Supporting Guidance; Research Councils UK: Swindon, UK, 2013; Available online: www.rcuk.ac.uk/documents/documents/RCUKOpenAccessPolicy.pdf (accessed on 24 February 2017).

31. Kennan, M. Learning to share: Mandates and open access. Libr. Manag. 2011, 32, 302-318. [CrossRef]

32. Kingsley, D.A.; Kennan, M.A. Open Access: The whipping boy for problems in scholarly publishing. Commun. Assoc. Inf. Syst. 2015, 37, 329-350.

33. Xia, J.; Gilchrist, S.B.; Smith, N.X.P.; Kingery, J.A.; Radecki, J.R.; Wilhelm, M.L.; Harrison, K.C.; Ashby, M.L.; Mahn, A.J. A review of open access self-archiving mandate policies. Portal Libr. Acad. 2012, 12, 85-102. [CrossRef]

34. Björk, B.C.; Laakso, M.; Welling, P.; Paetau, P. Anatomy of green open access. J. Assoc. Inf. Sci. Technol. 2014, 65, 237-250. [CrossRef]

35. Hoorn, E.; van der Graaf, M. Towards Good Practices of Copyright in Open Access Journals: A Study among Authors of Articles in Open Access Journals; JISC-SURF: Amsterdam, The Netherlands, 2005; Available online: https:/ / oerknowledgecloud.org/content/towards-good-practices-copyright-open-access-journ als-study-among-authors-articles-open-acce (accessed on 1 August 2017).

36. Gadd, E. UK university policy approaches towards the copyright ownership of scholarly works and the future of open access. Aslib J. Inf. Manag. 2017, 69, 95-114. [CrossRef]

37. Weedon, R. Policy Approaches to Copyright in HEIs: A Study for the JISC Committee for Awareness, Liaison and Training (JCALT); The Centre for Educational Systems: Glasgow, UK, 2000.

38. Shashi Nath, S.; Joshi, C.M.; Kumar, P. Intellectual property rights: Issues for creation of institutional repository. DESIDOC J. Libr. Inf. Technol. 2008, 28, 49-55. [CrossRef]

39. Fyfe, A.; Coate, K.; Curry, S.; Lawson, S.; Moxham, N.; Røstvik, C.M. Untangling Academic Publishing: A History of the Relationship between Commercial Interests, Academic Prestige and the Circulation of Research; University of St Andrews: Scotland, UK, 2017; Available online: https:/ / zenodo.org/record/546100\#.WTK4 eKP2bIU (accessed on 26 June 2017).

40. Rowley, J.; Johnson, F.; Sbaffi, L.; Frass, W.; Devine, E. Academics' behaviors and attitudes towards open access publishing in scholarly journals. J. Assoc. Inf. Sci. Technol. 2017, 68, 1201-1211. [CrossRef]

41. Hahn, S.E.; Wyatt, A. Business Faculty's Attitudes: Open Access, Disciplinary Repositories, and Institutional Repositories. J. Bus. Financ. Libr. 2014, 19, 93-113. [CrossRef]

42. Yang, Z.; Li, Y. University faculty awareness and attitudes towards open access publishing and the institutional repository: A case study. J. Libr. Sch. Commun. 2015, 3, 1210. [CrossRef]

43. Ponte, D.; Mierzejewska, B.I.; Klein, S. The transformation of the academic publishing market: Multiple perspectives on innovation. Electron. Mark. 2017, 27, 97-100. [CrossRef]

44. Metze, K. Bureaucrats, researchers, editors, and the impact factor: A vicious circle that is detrimental to science. Clinics 2010, 65, 937-940. [CrossRef] [PubMed]

45. Tunru, V. The Vicious Cycle of Scholarly Publishing. Available online: https://medium.com/flockademic/t he-vicious-cycle-of-scholarly-publishing-eef794937c9c (accessed on 19 November 2017).

46. Casadevall, A.; Fang, F.C. Causes for the persistence of impact factor mania. mBio 2014, 5, 1-5. [CrossRef]

47. Kim, J. Faculty self-archiving: Motivations and barriers. J. Am. Soc. Inf. Sci. Technol. 2010, 61, $1909-1922$. [CrossRef]

48. Laakso, M. Green open access policies of scholarly journal publishers: A study of what, when, and where self-archiving is allowed. Scientometrics 2014, 99, 475-494. [CrossRef]

49. Jamali, H.R. Copyright compliance and infringement in ResearchGate full-text journal articles. Scientometrics 2017, 112, 241-254. [CrossRef]

50. Gadd, E. Academics and Copyright Ownership: Ignorant, Confused or Misled? Available online: https: / scholarlykitchen.sspnet.org/2017/10/31/guest-post-academics-copyright-ownership-ignorant-c onfused-misled/ ?informz=1 (accessed on 9 December 2017).

51. Corrall, S. Designing libraries for research collaboration in the network world: An exploratory study. LIBER Q. 2014, 24, 17-48. [CrossRef] 
52. Shreeves, S.L. The role of repositories in the future of the journal. In The Future of the Academic Journal, 2nd ed.; Cope, B., Phillips, A., Eds.; Chandos Publishing: Oxford, UK, 2014; pp. 299-315, ISBN 9781843347835.

53. Johnson, L.; Adams Becker, S.; Estrada, V.; Freeman, A. NMC Horizon Report: 2015 Library Edition; The New Media Consortium: Austin, TX, USA, 2015; Available online: http://cdn.nmc.org/media/2015-nmc-horiz on-report-libraryEN.pdf (accessed on 8 March 2017).

54. Bowman, S.; Cotter, G.; Herlihy, B.; Noonan, E. It's not easy being green: Supporting implementation of an open access to publications policy at University College Cork. In Proceedings of the CONUL Annual Conference, Athlone, Ireland, 30-31 May 2017; Available online: https:/ / cora.ucc.ie/bitstream/handle/104 68/4070/CONUL2017_Beinggreen.pdf?sequence=2andisAllowed=y (accessed on 21 January 2018).

55. Keller, A. Library support for open access journal publishing: A needs analysis. Insights 2015, 28, 19-31. [CrossRef]

56. Cox, J. New Directions for Academic Libraries in Research Staffing: A Case Study at National University of Ireland Galway. New Rev. Acad. Libr. 2017, 23. [CrossRef]

57. Clay, D. Building scalable and sustainable services for researchers. In Developing Digital Scholarship: Emerging Practices in Academic Libraries; MacKenzie, A., Martin, L., Eds.; Facet: London, UK, 2016; pp. 121-138, ISBN 9781783301102.

58. Price, E.; Engelson, L.; Vance, C.; Richardson, R.; Henry, J. Open access and closed minds? Collaborating across campus to help faculty understand changing scholarly communications models. In Open Access and the Future of Scholarly Communication: Policy and Infrastructure; Smith, K., Dickson, K., Eds.; Rowman and Littlefield: Lanham, MD, USA, 2016; pp. 67-84, ISBN 9781442273023.

59. Posner, M. No half measures: Overcoming common challenges to doing digital humanities in the library. J. Libr. Adm. 2013, 53, 43-52. [CrossRef]

60. Vandegrift, M.; Varner, S. Evolving in common: Creating mutually supportive relationships between libraries and the digital humanities. J. Libr. Adm. 2013, 53, 67-78. [CrossRef]

61. Cox, J. Communicating new library roles to enable digital scholarship: A review article. New Rev. Acad. Libr. 2016, 22, 132-147. [CrossRef]

62. Tenopir, C.; Dalton, E.D.; Christian, L.; Jones, M.K.; McCabe, M.; Smith, M.; Fish, A. Imagining a gold open access future: Attitudes, behaviors, and funding scenarios among authors of academic scholarship. Coll. Res. Libr. 2017, 78, 824-843. [CrossRef]

63. Russell, J. How are universities putting policy into practice, from both library and research perspectives? Insights 2014, 27, 25-31. [CrossRef]

64. Sweeney, D. Working together more constructively towards open access. Inf. Serv. Use 2014, 34, 181-184. [CrossRef]

65. Larivière, V.; Haustein, S.; Mongeon, P. The oligopoly of academic publishers in the digital era. PLoS ONE 2015, 10, e0127502. [CrossRef] [PubMed]

66. Lawson, S.; Gray, J.; Mauri, M. Opening the Black Box of Scholarly Communication Funding: A Public Data Infrastructure for Financial Flows in Academic Publishing. Open Libr. Hum. 2016, 2, e10. [CrossRef]

67. Morrison, H.; Salhab, J.; Calvé-Genest, A.; Horava, T. Open access article processing charges: DOAJ survey May 2014. Publications 2015, 3, 1. [CrossRef]

68. Crotty, D. The UK Government Looks to Double Dip to Pay for Its Open Access Policy. Available online: http:/ / scholarlykitchen.sspnet.org/2014/02/06/the-uk-government-looks-to-double-dip-to-payfor-its-open-access-policy (accessed on 14 November 2017).

69. Bastos, F.; Vidotti, S.; Oddone, N. The University and its libraries: Reactions and resistance to scientific publishers. Inf. Serv. Use 2011, 31, 121-129. [CrossRef]

70. JISC. SHERPA Services. Available online: https://www.jisc.ac.uk/sherpa (accessed on 9 August 2017).

71. Morrison, H. Economics of scholarly communication in transition. First Monday 2013, 18. [CrossRef]

72. Frankel, S.; Nestor, S. Opening the Door: How Faculty Authors Can Implement an Open Access Policy at Their Institutions; Science Commons Covington et Burling LLP: Washington, DC, USA, 2010; Available online: http:/ / sciencecommons.org/wp-content/uploads/Opening-the-Door.pdf (accessed on 21 February 2017).

73. Dawson, P.H.; Yang, S.Q. Institutional Repositories, Open Access and Copyright: What Are the Practices and Implications? Sci. Technol. Libr. 2016, 35, 279-294. [CrossRef] 
74. Poynder, R. Open Access and Its Discontents: A British View from Outside the Sciences. Available online: https:/ / poynder.blogspot.co.uk/2017/12/open-access-and-its-discontents-british.html (accessed on 23 February 2018).

75. The Publishers Association. Scholarly Communications Licence. Available online: https://www.publishers .org.uk/policy-research/submissions/scholarly-communications-licence/ (accessed on 14 August 2017).

76. The Royal Historical Society. The UK Scholarly Communications Licence: What It Is, and Why It Matters for the Arts and Humanities. 2018. Available online: https://5hm1h4aktue2uejbs1hsqt31-wpengine.netdna-ssl .com/wp-content/uploads/2018/03/UK-SCL-March-2018.pdf (accessed on 16 February 2018).

77. Jones, S. Developments in Research Funder Data Policy. Int. J. Dig. Curation 2012, 7, 114-125. [CrossRef]

78. Erway, R. Starting the Conversation: University-Wide Research Data Management Policy; OCLC Research: Dublin, OH, USA, 2013; Available online: http:/ / www.oclc.org/content/dam/research/publications/library/2013/ 2013-08.pdf (accessed on 17 February 2018).

79. Taylor, M. Why Policy Fails-And How It Might Succeed. Available online: https://www.thersa.org/discove $\mathrm{r} /$ publications-and-articles/matthew-taylor-blog/2016/09/why-policy-fails-and-how-it-might-succeed (accessed on 18 July 2017).

80. Creswell, J.W. Research Design: Qualitative, Quantitative, and Mixed Methods Approaches, 4th ed.; Sage Publications: Thousand Oaks, CA, USA, 2013; ISBN 978-1452226101.

81. Bryman, A. Social Research Methods, 5th ed.; Oxford University Press: Oxford, UK, 2016; ISBN 978-0199689453.

82. Braun, V.; Clarke, V. Using thematic analysis in psychology. Qual. Res. Psychol. 2006, 3, 77-101. [CrossRef]

83. Curry, S. We Need to Talk about Open Access. Available online: http:/ / occamstypewriter.org/scurry/2012 /11/24/we-need-to-talk-about-open-access / (accessed on 9 January 2018).

84. Adema, J.; Stone, G.; Keene, C. Changing Publishing Ecologies: A Landscape Study of New University Presses and Academic-Led Publishing: A Report to JISC; JISC: Bristol, UK, 2017; Available online: https: / / repository.jisc.ac .uk/6666/1/Changing-publishing-ecologies-report.pdf (accessed on 8 April 2018).

85. Dodds, F. The changing copyright landscape in academic publishing. Learn. Publ. 2018, 270-275. [CrossRef]

86. UKRI. UK Research and Innovation. Available online: https:/ /www.ukri.org/ (accessed on 17 May 2018).

87. Pells, R. UK Research Funders Target Hybrid Open Access Charges. The Times Higher Education. 5 March 2018. Available online: https://www.timeshighereducation.com/news/uk-research-funders-target-hybri d-open-access-charges (accessed on 6 March 2018).

88. JISC. Discussion Paper: Considering the Implications of the Finch Report Five Years on; JISC Collections Content Strategy Group: London, UK, 2018; Available online: https://www.sconul.ac.uk/sites/default/files/Evolv ing $\% 20$ the $\% 20$ UK\%20Approach $\% 20$ to $\% 20$ OA $\% 20$ five $\% 20$ years $\% 20$ on $\% 20$ from $\% 20$ Finch.pdf (accessed on 3 March 2018).

(C) 2018 by the authors. Licensee MDPI, Basel, Switzerland. This article is an open access article distributed under the terms and conditions of the Creative Commons Attribution (CC BY) license (http://creativecommons.org/licenses/by/4.0/). 